\title{
Adjusted R Squared
}

National Cancer Institute

\section{Source}

National Cancer Institute. Adjusted R Squared. NCI Thesaurus. Code C85553.

The goodness of fit statistic for the terminal elimination phase, adjusted for the number of time points used in the estimation of Lambda $z$. 